\title{
Type 2 Diabetes Mellitus and Preoperative HbA1c Level Have no Consequence on Outcomes after Laparoscopic Sleeve Gastrectomy-a Cohort Study
}

\author{
Michał Wysocki ${ }^{1,2}$ - Maciej Walędziak ${ }^{3}$ Hady Razak Hady ${ }^{4} \cdot$ Mikołaj Czerniawski $^{4}$ - Monika Proczko-Stepaniak ${ }^{5}$. \\ Michał Szymański ${ }^{5}$. Natalia Dowgiałło-Wnukiewicz ${ }^{6}$ - Piotr Kozera ${ }^{6} \cdot$ Jacek Szeliga $^{7} \cdot$ Michał Orłowski $^{8}$. \\ Michał Pędziwiatr ${ }^{1,2} \cdot$ Magdalena Szopa $^{9} \cdot$ Andrzej Budzyński $^{1,2} \cdot$ Piotr Major $^{1,2}$ (iD)
}

Published online: 14 May 2019

(C) The Author(s) 2019

\begin{abstract}
Introduction Available clinical data on the influence of baseline $\mathrm{HbA}_{1 \mathrm{c}}$ postoperative morbidity and readmission after laparoscopic sleeve gastrectomy is scarce. This prompted us to conduct a multicenter retrospective study evaluating the influence of chronic hyperglycemia on postoperative course among patients undergoing laparoscopic sleeve gastrectomy (SG). We aimed to investigate the influence of baseline $\mathrm{HbA}_{1 \mathrm{c}}$ levels on postoperative outcomes in patients after SG.

Material and Methods We conducted a multicenter retrospective cohort study of consecutive patients who underwent SG from March 2017 to March 2018 in seven referral centers for bariatric surgery. Exclusion criteria were revision surgeries, different bariatric interventions, SG combined with other procedures, and lack of necessary data. Patients were divided into three groups depending on their preoperative glycated hemoglobin level $\left(\mathrm{HbA}_{1 \mathrm{c}}\right)<5.7 \%, 5.7-6.4 \%$, and $\geq 6.5 \%$. Primary endpoints were influence of $\mathrm{HbA}_{1 \mathrm{c}}$ on early and late postoperative morbidity, impact on prolonged length of hospital stay (LOS), and readmission rate.

Results The $\mathrm{HbA}_{1 \mathrm{c}}<5.7 \%$ group comprised 842 (49\%) patients, $\mathrm{HbA}_{1 \mathrm{c}} 5.7-6.4 \%$ comprised $587(34 \%)$, and $\mathrm{HbA}_{1 \mathrm{c}} \geq 6.5 \%$ comprised $289(17 \%)$. Overall morbidity was $6.23 \%$; this did not differ among groups $(p=0.571)$. Three patients died postoperatively. Late postoperative morbidity was comparable among groups $(p=0.312)$. The ratio of prolonged LOS and readmission did not differ among groups $(p=0.363$ and 0.571$)$. ROC analysis revealed that $\mathrm{HbA}_{1 \mathrm{c}}>7.3 \%$ increased OR for hospital readmission $(p=0.007)$.
\end{abstract}

Piotr Major

piotr.major@uj.edu.pl

Michał Wysocki

m.wysocki@doctoral.uj.edu.pl

Maciej Walędziak

maciej.waledziak@gmail.com

Hady Razak Hady

hadyrazakh@wp.pl

Mikołaj Czerniawski

mikolajczerniawski@gmail.com

Monika Proczko-Stepaniak

mproczko@gumed.edu.pl

Michał Szymański

szymanski.dred@gmail.com

Natalia Dowgiałło-Wnukiewicz

natalia.dowgiallo@gmail.com

\author{
Piotr Kozera \\ piotr.jaroslaw.kozera@gmail.com \\ Jacek Szeliga \\ jacky2@wp.pl \\ Michał Orłowski \\ mikeorlowski@gmail.com \\ Michał Pedziwiatr \\ michal.pedziwiatr@uj.edu.pl \\ Magdalena Szopa \\ magdalena.szopa@uj.edu.pl \\ Andrzej Budzyński \\ andrzej.budzynski@uj.edu.pl
}

Extended author information available on the last page of the article 
Conclusion Preoperative $\mathrm{HbA}_{1 \mathrm{c}}$ does not affect postoperative morbidity and prolonged LOS after SG. Patients with $\mathrm{HbA}_{1 \mathrm{c}}>$ $7.3 \%$ have an increased chance of hospital readmission.

Keywords Laparoscopic sleeve gastrectomy $\cdot$ Glycated hemoglobin $\cdot$ Postoperative morbidity $\cdot$ Postoperative mortality $\cdot$ Length of hospital stay $\cdot$ Readmission

\section{Introduction}

It is believed that almost every surgical procedure induces a stress response that may be responsible for morbidity and mortality [1]. Patients with diabetes mellitus type 2 (DM2) and chronic hyperglycemia, reflected by elevated glycated hemoglobin level $\left(\mathrm{HbA}_{1 \mathrm{c}}\right)$, may be particularly exposed to perioperative morbidity from diabetes-related complications $[2,3]$. DM2 and increased mortality and morbidity in cardiac surgery are connected $[4,5]$. This association is less clearly documented in other surgical fields [6-10].

$\mathrm{HbA}_{1 \mathrm{c}}$ has been proposed as a reliable indicator of glycemic status in the preoperative period because it is unaffected by fasting status. Furthermore, it is less affected by stress hyperglycemia than glycemic status $[11,12]$. It has therefore been accepted as an appropriate method for diagnosing and monitoring DM2 [13, 14]. A meta-analysis investigating the association between $\mathrm{HbA}_{1 \mathrm{c}}$ and surgical outcomes in different branches of surgery has shown conflicting results and did not include bariatric surgery [15]. We found scarce clinical data regarding the influence of baseline $\mathrm{HbA}_{1 \mathrm{c}}$ on postoperative morbidity and readmission after laparoscopic sleeve gastrectomy. This prompted us to conduct this multicenter retrospective study, evaluating the influence of chronic hyperglycemia on postoperative course among patients undergoing laparoscopic sleeve gastrectomy (SG). To the best of our knowledge, this problem has not yet been investigated [16-20].

\section{Aim of the Study}

The aim of this study was to assess the influence of baseline $\mathrm{HbA}_{1 \mathrm{c}}$ levels on postoperative outcomes in patients undergoing laparoscopic sleeve gastrectomy.

\section{Material and Methods}

\section{Methods}

A retrospective cohort study was used to analyze consecutive patients who underwent surgical treatment for morbid obesity in seven referral bariatric centers in Poland from March 2017 to March 2018. Each participating center provided specific data, which were processed and used in the overall analysis.
The study was designed and described according to the STROBE guidelines for observational studies [21]. The included patients underwent laparoscopic sleeve gastrectomy. Each patient qualified for surgical treatment in accordance with the Polish Guidelines for Metabolic and Bariatric Surgery [22]. Exclusion criteria were revision surgeries, different bariatric operations, sleeve gastrectomy combined with other procedures, and lack of necessary data (only patients with complete follow-up were included). All procedures were performed laparoscopically using comparable surgical techniques, and perioperative care was based on standardized protocols, which ensured reliable data comparison. $\mathrm{HbA}_{1 \mathrm{c}}$ was measured on the day of hospital admission. Patients were divided into three groups depending on their preoperative glycated hemoglobin level $\left(\mathrm{HbA}_{1 \mathrm{c}}\right) \mathrm{HbA}_{1 \mathrm{c}}<5.7 \%, \mathrm{HbA}_{1 \mathrm{c}}$ 5.7-6.4\%, and $\mathrm{HbA}_{1 \mathrm{c}} \geq 6.5 \%$. These values equate to the American Diabetes Association definitions of normal $\mathrm{HbA}_{1 \mathrm{c}}$, prediabetes, and diabetes mellitus [13]. Baseline characteristics were sex, age, body mass index (BMI), and relevant comorbidities.

Primary endpoints included the influence of the $\mathrm{HbA}_{1 \mathrm{c}}$ level on early postoperative morbidity ( 30 days) and late postoperative morbidity (12 months excluding the first 30 days), including mortality. influence on the rate of prolonged length of hospital stay (prolonged LOS), and readmission rate. Secondary endpoints were to determine $\mathrm{HbA}_{1 \mathrm{c}}$ cut-off points and when the odds ratio (OR) of primary endpoints significantly rose.

\section{Definitions}

Postoperative morbidity was defined as any deviation from the standard postoperative course that required additional measures to correct. LOS was defined as the period from surgery to discharge. Prolonged LOS was defined as $>4$ days because the hospitalization for surgical bariatric treatment was planned for a maximum of 4 days. Readmissions were analyzed only if they occurred in the indexed hospitals.

\section{Ethics}

All procedures performed in the study involving human participants were in accordance with the ethical standards of the institutional and national research committee and with the 1964 Helsinki declaration and its later 
Table 1 General characteristics

\begin{tabular}{ll}
$N(\%)$ & $1718(100 \%)$ \\
\hline Males/females, $n(\%)$ & $585 / 1133(34 \% / 66 \%)$ \\
Median age, years (IQR) & $41(35-51)$ \\
Median BMI, $\mathrm{kg} / \mathrm{m}^{2}(\mathrm{IQR})$ & $44.1(40.3-48.77)$ \\
Arterial hypertension, $n(\%)$ & $787(45.8 \%)$ \\
Obstructive sleep apnea, $n(\%)$ & $218(12.69 \%)$ \\
Median operative time, $\min (\mathrm{IQR})$ & $70(55.5-90)$
\end{tabular}

amendments or comparable ethical standards. Formal consent was not required for this study.

\section{Statistical Analysis}

Calculations were performed using Statistica 13.5 software (StatSoft@, Tulsa, OK, USA). Continuous values were presented as means with standard deviations or medians with interquartile ranges when appropriate. Quantitative variables were compared using the Kruskal-Wallis ANOVA with post hoc multiple comparisons of ranges. Qualitative variables were compared using the Pearson $\chi$-square with or without Yates' correction. Receiver operating characteristic (ROC) curves were used to set $\mathrm{HbA}_{1 \mathrm{c}}$ cutoffs; then, univariate logistic regression models were built. Significant univariate logistic regression was adjusted for relevant intergroup baseline differences in multivariate analyses to calculate the OR with $95 \%$ confidence interval $(\mathrm{CI}) . P$ values $\leq$ 0.05 were considered statistically significant.

\section{Material}

The study group comprised 1718 patients from seven bariatric centers in Poland. The study population is characterized in Table 1.

\section{Results}

\section{Group Characteristics}

Group characteristics depending on the level of glycated hemoglobin are presented in Table 2. Median $\mathrm{HbA}_{1 \mathrm{c}}$ was $5.7 \%$ (5.3\%-6.1\%). Sex distribution significantly differed between $\mathrm{HbA}_{1 \mathrm{C}}$ groups, with an increasing prevalence of male patients from the $\mathrm{HbA}_{1 \mathrm{C}}<5.7 \%$ to $\mathrm{HbA}_{1 \mathrm{C}} \geq 6.5 \%$ groups $(29 \%, 35 \%$, and $47 \% ; p<0.001)$. Multiple range comparisons in KruskalWallis ANOVA showed a significant increase in age from the $\mathrm{HbA}_{1 \mathrm{C}}<5.7 \%$ to $\mathrm{HbA}_{1 \mathrm{C}} \geq 6.5 \%$ groups $(p<0.001)$. This was also the same for patients' preoperative BMI.

\section{Primary Outcomes}

Table 3 presents postoperative outcomes of the whole study population.

The overall morbidity rate was $6.23 \%$ (107 patients); this did not differ among groups $(p=0.571)$. Neither the early nor late postoperative morbidity rate differed among groups (68 patients, $p=0.445$ and 39 patients, $p=0.312$ respectively). Details of clinical outcomes in each group are presented in Table 4. There were three early postoperative deaths $(0.17 \%)$; these were due to urosepsis $\left(\mathrm{HbA}_{1 \mathrm{c}}=6.7 \%\right)$, gastric leak $\left(\mathrm{HbA}_{1 \mathrm{c}}=7.8 \%\right)$, and gastric leak and pancreatitis $\left(\mathrm{HbA}_{1 \mathrm{c}}=5.2 \%\right)$. There were no deaths in the late postoperative period. The ratio of prolonged LOS did not differ among groups $(p=0.363)$. The readmission rate did not differ significantly among groups $(p=0.571)$. Patients with no preoperative diagnosis of DM2 who were in the $\mathrm{HbA}_{1 \mathrm{c}} \geq$ $6.5 \%$ group did not have increased ORs for early postoperative (OR 0.62 , 95\% CI $0.22-1.73, p=0.361$ ) or late postoperative complications $(1.87$, 95\% CI $0.77-4.53$, $p=0.167)$. Those patients also did not have increased ORs for prolonged LOS (OR 1.42, 95\%CI 0.65-3.08, $p=0.379)$ or hospital readmission (OR $0.38(0.05-$ 2.85, $p=0.349$ ).

Table 2 Group characteristics

\begin{tabular}{|c|c|c|c|c|}
\hline & $\mathrm{HbA}_{1 \mathrm{c}}<5.7 \%$ & $\mathrm{HbA}_{1 \mathrm{c}} 5.7-6.4 \%$ & $\mathrm{HbA}_{1 \mathrm{c}} \geq 6.5 \%$ & $p$ value \\
\hline$N(\%$ total $)$ & $842(49 \%)$ & $587(34 \%)$ & $289(17 \%)$ & $\mathrm{N} / \mathrm{a}$ \\
\hline Diabetes mellitus type $2, n(\%)$ & $77(8.95 \%)$ & $132(22.39 \%)$ & $134(46.37 \%)$ & \multirow[t]{2}{*}{$<0.001$} \\
\hline No diagnosis of diabetes mellitus type $2, n(\%)$ & $765(91.05 \%)$ & $455(77.61 \%)$ & $155(53.63 \%)$ & \\
\hline Males/females, $n(\%)$ & $243 / 599(29 \% / 71 \%)$ & $205 / 382(35 \% / 65 \%)$ & $137 / 152(47 \% / 53 \%)$ & $<0.001$ \\
\hline Median age, years (IQR) & $38(32-47)$ & $43(35-53)$ & $48(40-57)$ & $<0.001$ \\
\hline Median BMI, $\mathrm{kg} / \mathrm{m}^{2}$ (IQR) & $43(40-48)$ & $44(40-49)$ & $47(42-52)$ & $<0.001$ \\
\hline Arterial hypertension, $n(\%)$ & $287(34 \%)$ & $309(53 \%)$ & $191(66 \%)$ & $<0.001$ \\
\hline Obstructive sleep apnea, $n(\%)$ & $66(8 \%)$ & $89(15 \%)$ & $63(22 \%)$ & $<0.001$ \\
\hline
\end{tabular}


Table 3 Postoperative outcomes

\begin{tabular}{lr}
\hline Median LOS, days (IQR) & $3(3-4)$ \\
Prolonged LOS, $n(\%)$ & $94(5.47 \%)$ \\
Overall morbidity, $n(\%)$ & $107(6.23 \%)$ \\
Early postoperative morbidity, $n(\%)$ & $68(3.96 \%)$ \\
Early postoperative mortality, $n(\%)$ & $3(0.17 \%)$ \\
Late postoperative morbidity (excluding 1st postoperative & $39(2.27 \%)$ \\
$\quad$ month), $n(\%)$ & \\
Readmissions, $n(\%)$ & $27(1.57 \%)$ \\
\hline
\end{tabular}

\section{Secondary Outcomes}

Surprisingly, analyses of the ROC curves did not reveal any $\mathrm{HbA}_{1 \mathrm{c}}$ cutoff point that would significantly increase ORs for primary endpoints. The only significant finding was that patients in the $\mathrm{HbA}_{1 \mathrm{c}}>7.3 \%$ group had a higher likelihood of hospital readmission, as shown in Table 5. In multivariate logistic regression analysis, $\mathrm{HbA}_{1 \mathrm{c}}$ remained the only significant factor for readmissions (OR 4.59, 95\%CI 1.61-13.06, $p=0.004$ ).

\section{Discussion}

This is the first study to investigate the influence of preoperative $\mathrm{HbA}_{1 \mathrm{c}}$ levels on postoperative outcomes after laparoscopic sleeve gastrectomy. Our literature search revealed that the available information in the literature regarding this subject is limited. Previous studies predominantly analyzed patients after gastric bypass surgery. No studies investigating laparoscopic sleeve gastrectomy were found. Our study showed that baseline $\mathrm{HbA}_{1 \mathrm{c}}$ levels did not increase the likelihood of early and late postoperative morbidity or prolonged LOS. Further analysis revealed that patients with baseline $\mathrm{HbA}_{1 \mathrm{c}}>7.3 \%$ had increased OR for hospital readmission.

The influence of baseline preoperative glycated hemoglobin $\mathrm{HbA}_{1 \mathrm{c}}$ levels on surgical morbidity has not been clearly determined, as presented in a systematic review by Rollins et al. [15]. $\mathrm{HbA}_{1 \mathrm{c}}$ was validated as an appropriate method for diagnosing
DM2 by diabetes specialist consensus [3, 13]. However, in the Polish Guidelines on the management of diabetic patients, $\mathrm{HbA}_{1 \mathrm{c}}$ is not recommended for diagnosing DM2 [23]. DM2 is diagnosed based on the fasting blood glucose level and/or fasting oral glucose tolerance test. In our study, 155 patients were in the $\mathrm{HbA}_{1 \mathrm{c}} \geq 6.5 \%$ group. Although they should have been diagnosed and treated for DM2, the routine preoperative assessment did not diagnose them with DM2. Despite this, the early and late postoperative morbidity did not increase.

The available literature analyzed the influence of $\mathrm{HbA}_{1 \mathrm{c}}$ on postoperative outcomes after laparoscopic Roux-en-Y gastric bypass (LRYGB). Perna et al. published a study comprising 468 patients who underwent gastric bypass for morbid obesity [18]. They divided patients into three groups depending on their $\mathrm{HbA}_{1 \mathrm{c}}$ level $\mathrm{HbA}_{1 \mathrm{c}}<6.5 \%, 6.5-7.9 \%$, and $\geq 8.0 \%$. They found no difference in overall complications or mortality. A year later, Rawlins et al. published a study analyzing the results of surgical treatment of 342 morbidly obese patients with DM2 who underwent LRYGB [19]. They found no significant increase in 1-year postoperative morbidity in patients with $>7 \% \mathrm{HbA}_{1 \mathrm{c}}$ [19]. Cruijsen et al. designed a single-center observational study involving $85 \mathrm{DM} 2$ patients with a $\mathrm{BMI} \geq$ $35 \mathrm{~kg} / \mathrm{m}^{2}$ who were scheduled for LRYGB [17]. Preoperative glycemic control was comparable in patients with and without surgical complications because $\mathrm{HbA}_{1 \mathrm{c}}$ levels were comparable in both groups [17]. In our study, patients' early postoperative morbidity was comparable among groups. Similar findings were also true for late postoperative morbidity. Neither did we find differences in the $\mathrm{HbA}_{1 \mathrm{c}}$ levels in the case of patients with and without prolonged LOS. Chuah et al. designed GLUCOSURG-pre RCT in which he divided DM2 patients to directly undergo LRYGB or to receive intensive preoperative DM2 treatment to preoperatively normalize $\mathrm{HbA}_{1 \mathrm{c}}$ levels [16]. Shockingly, neither LOS, nor 30-day perioperative complications differed among groups.

Our study improves the current knowledge of the influence of preoperative glucose metabolic state on postoperative $\mathrm{SG}$ outcomes. The $\mathrm{HbA}_{1 \mathrm{c}}$ level represents median blood glucose concentrations in the past 4 months, which should be the period

Table 4 Clinical outcomes

\begin{tabular}{|c|c|c|c|c|}
\hline & $\mathrm{HbA}_{1 \mathrm{c}}<5.7 \%$ & $\mathrm{HbA}_{1 \mathrm{c}} 5.7-6.4 \%$ & $\mathrm{HbA}_{1 \mathrm{c}} \geq 6.5 \%$ & $p$ value \\
\hline$N(\%$ total $)$ & $842(49 \%)$ & $587(34 \%)$ & $289(17 \%)$ & $\mathrm{N} / \mathrm{a}$ \\
\hline Overall morbidity, $n(\%)$ & $47(5.58 \%)$ & $39(6.64 \%)$ & $21(7.27 \%)$ & 0.571 \\
\hline Early postoperative morbidity, $n(\%)$ & $29(3.44 \%)$ & $28(4.77 \%)$ & $11(3.81 \%)$ & 0.445 \\
\hline Early postoperative mortality, $n(\%)$ & $1(0.12 \%)$ & 0 & $2(0.69 \%)$ & 0.124 \\
\hline Late postoperative morbidity, $n(\%)$ & $18(2.14 \%)$ & $11(1.87 \%)$ & $10(3.46 \%)$ & 0.312 \\
\hline Prolonged LOS, $n(\%)$ & $40(4.75 \%)$ & $31(5.28 \%)$ & $21(7.28 \%)$ & 0.363 \\
\hline Prolonged LOS $>3$ days & $281(33.37 \%)$ & $150(25.56 \%)$ & $103(35.64 \%)$ & 0.017 \\
\hline Prolonged LOS $>5$ days & $13(1.54 \%)$ & $18(3.07 \%)$ & $10(3.46 \%)$ & 0.196 \\
\hline Readmissions, $n(\%)$ & $47(5.58 \%)$ & $37(6.30 \%)$ & $21(7.28 \%)$ & 0.571 \\
\hline
\end{tabular}


Table 5 Cutoff points of $\mathrm{HbA}_{1 \mathrm{c}}$ for clinical outcomes

\begin{tabular}{|c|c|c|c|c|}
\hline & Cutoff for $\mathrm{HbA}_{1 \mathrm{c}}$ & AUC $(95 \% \mathrm{CI})$ & OR $(95 \% \mathrm{CI})$ & $p$ value \\
\hline Overall morbidity & $5.9 \%$ & $0.54(0.48-0.60)$ & $0.94(0.61-1.44)$ & 0.777 \\
\hline Early postoperative morbidity & $5.9 \%$ & $0.55(0.49-0.62)$ & $1.10(0.66-1.84)$ & 0.702 \\
\hline Early postoperative mortality & $6.7 \%$ & $0.67(0.26-1.00)$ & $3.66(0.33-40.64)$ & 0.290 \\
\hline Late postoperative morbidity & $5.9 \%$ & $0.52(0.42-0.63)$ & $0.64(0.30-1.36)$ & 0.244 \\
\hline Prolonged LOS & $5.5 \%$ & $0.54(0.46-0.62)$ & $1.37(0.76-2.46)$ & 0.293 \\
\hline Readmissions & $7.3 \%$ & $0.55(0.42-0.67)$ & $3.95(1.46-10.68)$ & 0.007 \\
\hline
\end{tabular}

of intensive preoperative preparations. There were patients whose fasting glucose level was either normal or who would be diagnosed with glucose intolerance; however, according to $\mathrm{HbA}_{1 \mathrm{c}}$, they would have been diagnosed with DM2. Fortunately, this did not translate into postoperative morbidity and mortality. Patients with high preoperative $\mathrm{HbA}_{1 \mathrm{c}}$ levels who underwent SG were at increased risk of hospital readmission. Further studies such as RCT similar to GLUCOSURG that focuses on patients with DM2 undergoing SG are required to extensively assess this subject. Additional data on the influence of gut hormone changes, stress response, variability of glucose concentrations, and preoperative glucose metabolic state would be useful to build a comprehensive answer to the question of the significance of preoperative glycemic control improvement for postoperative safety [12, 25, 26]. [24]

\section{Limitations}

The results of our study are limited by several aspects typical for observational multicenter reports. This was a nonrandomized analysis and our groups were demographically heterogeneous and differed in preoperative factors. Furthermore, as the data were collected separately from seven bariatric centers using different electronic systems, some necessary information were lacking in our initial population, so we had to exclude some patients. We did not record postoperative events that occurred outside the indexed hospitals. Follow-up was complete in $86 \%$ of patients. The end of the study was in March 2018 and follow-up of $14 \%$ of patients was limited to 9 months. We did not analyze perioperative care protocols or operative techniques in each hospital. Another limitation is the fact that we have not investigated diabetes remission and bariatric effects 1 year after surgery.

\section{Conclusions}

$\mathrm{HbA}_{1 \mathrm{c}} \geq 6.5 \%$ is common among patients undergoing SG $(17 \%)$. Preoperative $\mathrm{HbA}_{1 \mathrm{c}}$ level is not associated with postoperative outcomes after laparoscopic sleeve gastrectomy, including postoperative morbidity and prolonged LOS. Patients with $\mathrm{HbA}_{1 \mathrm{c}}>7.3 \%$ have a higher risk of hospital readmission.

\section{Compliance with Ethical Standards}

Conflict of Interest All authors declare no conflicts of interest.

Informed Consent Informed consent was obtained from all individual participants included in the study.

Open Access This article is distributed under the terms of the Creative Commons Attribution 4.0 International License (http:// creativecommons.org/licenses/by/4.0/), which permits unrestricted use, distribution, and reproduction in any medium, provided you give appropriate credit to the original author(s) and the source, provide a link to the Creative Commons license, and indicate if changes were made.

\section{References}

1. Finnerty CC, Mabvuure NT, Ali A, et al. The surgically induced stress response. JPEN J Parenter Enteral Nutr [Internet]. 2013;37:21S-9S.

2. Valentine NA, Alhawassi TM, Roberts GW, et al. Detecting undiagnosed diabetes using glycated haemoglobin: an automated screening test in hospitalised patients. Med J Aust. 2011;194:160-4.

3. American Diabetes Association AD. 3. Comprehensive medical evaluation and assessment of comorbidities. Diabetes Care [Internet]. 2017;40:S25-32. Available from: http://www.ncbi.nlm. nih.gov/pubmed/27979890

4. Carson JL, Scholz PM, Chen AY, et al. Diabetes mellitus increases short-term mortality and morbidity in patients undergoing coronary artery bypass graft surgery. J Am Coll Cardiol. 2002;40:418-23.

5. Thourani VH, Weintraub WS, Stein B, et al. Influence of diabetes mellitus on early and late outcome after coronary artery bypass grafting. Ann Thorac Surg [Internet]. 1999;67:1045-52. Available from: http://www.ncbi.nlm.nih.gov/pubmed/10320249

6. Little SA, Jarnagin WR, DeMatteo RP, et al. Diabetes is associated with increased perioperative mortality but equivalent long-term outcome after hepatic resection for colorectal cancer. J Gastrointest Surg. 2002;6:88-94.

7. Hughes K, Jackson JD, Prendergast TI, et al. Diabetes mellitus is not associated with major morbidity following open abdominal aortic aneurysm repair. J Surg Res [Internet]. 2013;184:751-4. Available from: http://www.sciencedirect.com/science/article/pii/ S0022480413004034

8. Yeh C-C, Liao C-C, Chang Y-C, et al. Adverse outcomes after noncardiac surgery in patients with diabetes: a nationwide population-based retrospective cohort study. Diabetes care [Internet]. 2013;36:3216-21. Available from: http://www. pubmedcentral.nih.gov/articlerender.fcgi?artid=3781492\&tool= pmcentrez\&rendertype $=$ abstract 
9. Ata A, Valerian BT, Lee EC, et al. The effect of diabetes mellitus on surgical site infections after colorectal and noncolorectal general surgical operations. Am Surg. 2010;76:697-702.

10. Krolikowska M, Kataja M, Poyhia R, et al. Mortality in diabetic patients undergoing non-cardiac surgery: a 7-year follow-up study. Acta Anaesthesiol Scand. 2009;53:749-58.

11. Greci LS, Kailasam M, Malkani S, et al. Utility of HbA1c levels for diabetes case finding in hospitalized patients with hyperglycemia. Diabetes Care [Internet]. 2003;26:1064-8. Available from: http:// care.diabetesjournals.org/content/26/4/1064.full-text.pdf

12. Wysocki M, Szopa M, Stefura T, Dudek A, Torbicz G, Gajewska N, et al. Continuous glucose monitoring in bariatric patients undergoing laparoscopic sleeve gastrectomy and laparoscopic Roux-en-Y gastric bypass. Obes Surg 2018;

13. The International Expert Committee. International Expert Committee report on the role of the $\mathrm{A} 1 \mathrm{C}$ assay in the diagnosis of diabetes. Diabetes Care [Internet]. 2009;32:1327-34. Available from: http://care.diabetesjournals.org/cgi/doi/10.2337/dc09-9033

14. American Diabetes Association, Of D, Mellitus D, American Diabetes Association. Diagnosis and classification of diabetes mellitus. Diabetes Care [Internet]. 2014;37:81-90. Available from: http://www.ncbi.nlm.nih.gov/pubmed/24357215

15. Rollins KE, Varadhan KK, Dhatariya K, et al. Systematic review of the impact of $\mathrm{HbAlc}$ on outcomes following surgery in patients with diabetes mellitus. Clin Nutr [Internet]. 2015;35:1-10. Available from: http:/linkinghub.elsevier.com/retrieve/pii/S0261561415000825

16. Chuah LL, Miras AD, Papamargaritis D, et al. Impact of perioperative management of glycemia in severely obese diabetic patients undergoing gastric bypass surgery. Surg Obes Relat Dis. 2015;11: 578-84.

17. Cruijsen M, Koehestani P, Huttjes S, et al. Perioperative glycaemic control in insulin-treated type 2 diabetes patients undergoing gastric bypass surgery. Neth J Med. 2014;72:202-9.

18. Perna M, Romagnuolo J, Morgan K, et al. Preoperative hemoglobin A1c and postoperative glucose control in outcomes after gastric bypass for obesity. Surg Obes Relat Dis. 2012;8:685-90.

19. Rawlins L, Rawlins MP, Brown CC, et al. Effect of elevated hemoglobin A1c in diabetic patients on complication rates after Roux-enY gastric bypass. Surg Obes Relat Dis [Internet]. 2013;9:749-52. Available from: http://www.ncbi.nlm.nih.gov/pubmed/22884300

20. Zaman JA, Shah N, Leverson GE, et al. The effects of optimal perioperative glucose control on morbidly obese patients undergoing bariatric surgery. Surg Endosc [Internet]. 2017;31:1407-13. Available from: http://link.springer.com/10.1007/s00464-016-5129-x

21. Elm E, Altman DG, Egger M, et al. The Strengthening the Reporting of Observational Studies in Epidemiology (STROBE) statement: guidelines for reporting observational studies [Internet]. Lancet. 2007;370: 1453-7. Available from: http://onlinelibrary.wiley.com/o/cochrane/ clcmr/articles/CMR-11777/frame.html.

22. Budzyński A, Major P, Głuszek S, et al. Polskie rekomendacje w zakresie chirurgii bariatrycznej i metabolicznej. Med Prakt - Chir. 2016;6:13-25.

23. Diabetes Poland. Guidelines on the management of diabetic patients. A position of diabetes Poland. Clin Diabetol. 2017;6:1-80.

24. Nathan D, Buse J, Davidson M, et al. Medical management of hyperglycemia in type 2 diabetes : a consensus algorithm. Diabetes care [Internet]. 2009;32:193-203. Available from: https://media-proquestcom.ezproxy.uwe.ac.uk/media/pq/classic/doc/1124917791/fmt/pi/rep/ NONE?cit\%3Aauth=Nathan\%2C+David+M\%3BBuse $\% 2 \mathrm{C}+\mathrm{John}+$ B\%3BDavidson\%2C+Mayer+B\%3BHeine\%2C+Robert+J\%3Bet+ al\&cit\%3Atitle=Management+of + Hyperglycemia + in + Type $+2+$ Diabetes\%3A+A+Co

25. Major P, Matłok M, Pędziwiatr M, et al. Changes in levels of selected incretins and appetite-controlling hormones following surgical treatment for morbid obesity. Videosurgery other Miniinvasive Tech [Internet]. 2015;10:458-65. https://doi.org/10.5114/wiitm. 2015.54003

26. Wroblewski E, Swidnicka-Siergiejko A, Hady HR, et al. Variation in blood levels of hormones in obese patients following weight reduction induced by endoscopic and surgical bariatric therapies. Cytokine. 2016;77:56-62.

27. Wysocki M, Szopa M, Stefura T, Dudek A, Torbicz G, Gajewska N, et al. Continuous glucose monitoring in bariatric patients undergoing laparoscopic sleeve gastrectomy and laparoscopic Roux-En-Y gastric bypass. Obes Surg 2019;29:1317-26. https://doi.org/10. 1007/s11695-018-03684-5.

Publisher's Note Springer Nature remains neutral with regard to jurisdictional claims in published maps and institutional affiliations.

\section{Affiliations}

\section{Michał Wysocki ${ }^{1,2} \cdot$ Maciej Walędziak $^{3} \cdot$ Hady Razak Hady ${ }^{4} \cdot$ Mikołaj Czerniawski $^{4} \cdot$ Monika Proczko-Stepaniak $^{5}$. Michał Szymański ${ }^{5}$ - Natalia Dowgiałło-Wnukiewicz ${ }^{6}$. Piotr Kozera ${ }^{6}$ - Jacek Szeliga ${ }^{7}$. Michał Orłowski ${ }^{8}$. Michał Pędziwiatr ${ }^{1,2} \cdot$ Magdalena Szopa $^{9} \cdot$ Andrzej Budzyński $^{1,2} \cdot$ Piotr Major $^{1,2}$ (i)}

1 2nd Department of General Surgery, Jagiellonian University Medical College, Kraków, Poland

2 Training and Innovation in Surgery (CERTAIN Surgery), Centre for Research, Krakow, Poland

3 Department of General, Oncological, Metabolic and Thoracic Surgery, Military Institute of Medicine, Warsaw, Poland

4 First Clinical Department of General and Endocrine Surgery, Medical University of Bialystok, Bialystok, Poland

5 Chair and Clinic of General, Minimally Invasive and Elderly Surgery, University of Warmia \& Mazury, Olsztyn, Poland
6 Department of General, Gastroenterological, and Oncological Surgery Collegium Medicum, Nicolaus Copernicus University, Torun, Poland

7 General and Vascular Surgery Department, Ceynowa Hospital, Wejherowo, Poland

8 Department of General, Endocrine and Transplant Surgery, Medical University of Gdansk, Gdansk, Poland

9 Department of Metabolic Diseases, Jagiellonian University Medical College, Krakow, Poland 